"This is an accepted manuscript of an article published by Mark Allen Healthcare in British Journal of Healthcare Management, available online at

http://www.magonlinelibrary.com/doi/10.12968/bjhc.2017.23.2.56 it is not the copy of record.

Copyright ( 2017, Mark Allen Healthcare."

\title{
Looking beyond tasks to develop flexible leadership
}

\section{Key points:}

Ideas and practice around transformational leadership

The embedded nature of task-focused work

Leadership development programmes and their content

Facilitating reflective practice

Command and control hierarchies as a barrier to transformational leadership

\section{Abstract}

There is a determination within health and social care to make leaders and leadership better and more able to face the challenges presented by an everchanging social, political and organisational landscape. However, this determination is not without difficulties, especially the challenge of changing existing work place culture and climate. This paper reports on the findings of an evaluation of a leadership development programme delivered to senior leaders in health and social care. It uses qualitative data to demonstrate that even in a safe and risk-free environment health and social care leaders approached a hypothetical scenario in a defensive, hierarchical and expert-led manner and only after they were given 'expert' permission to change leadership style did they act collectively and seek to adopt a transformational style of leadership.

\section{Introduction}


"This is an accepted manuscript of an article published by Mark Allen Healthcare in British Journal of Healthcare Management, available online at

http://www.magonlinelibrary.com/doi/10.12968/bjhc.2017.23.2.56 it is not the copy of record.

Copyright (C) 2017, Mark Allen Healthcare."

It has become something of a truism in British public policy that the National Health Service (NHS) is in a state of 'permanent revolution'. As a result of the almost constant set of changes around how we manage and deliver health care, it has also become a mantra that 'the NHS needs good leaders' (Francis 2013 amongst many others). Accordingly, we have seen the development of an organisation (the NHS Leadership Academy) and a growth in the number of leadership development programmes (e.g. Nye Bevan; Mary Seacole amongst others), all aimed at improving the leadership capacity and capability of health and social welfare professionals. However, whilst there is an undoubted determination to improve leaders and leadership within the NHS and thereby ensuring that leaders and leadership has the dynamic and flexible approach needed in a constantly changing environment, the processes and practices are not without their own challenges.

This paper reports on the findings of an academic evaluation of a leadership development initiative delivered to senior health and social care professionals. It begins with a brief review of the literature around leadership in the NHS; it then offers an overview of the methods used in the study. From there, it provides a review of the main findings of the qualitative research data. The paper concludes by arguing that whilst there is an appetite for flexible and innovative leadership, when faced with a 'problem' which needs 'solving', NHS leadership resorts to its default task-and roleoriented approach.

\section{A brief word on leaders, leadership and the current knowledge base}


"This is an accepted manuscript of an article published by Mark Allen Healthcare in British Journal of Healthcare Management, available online at

http://www.magonlinelibrary.com/doi/10.12968/bjhc.2017.23.2.56 it is not the copy of record.

Copyright (C) 2017, Mark Allen Healthcare."

It is important to begin this section with a distinction between 'leader' and 'leadership' as what follows is concerned with the latter and not the former. For our purposes, we are not concerned with the development of individual leaders rather the focus of this paper and its empirical base is on the development of leadership, which we take to mean:

'...the development of the capacity of groups and organisations for leadership as a shared and collective process... (West et al 2015: 3)

This focus on leadership rather than leaders makes the paper important because as Kim and Newby-Bennett (2012) note there have been very few solid academic studies around leadership development within a healthcare setting.

West et al (2015), in their comprehensive literature review of health leadership, suggest that transformational leadership theory is currently the most influential approach in leadership development within the NHS and has been for at least two decades. On reflection, this is unsurprising given the degree of change the NHS has continually had to face. There also appears to be a general agreement that leaders who can face the changes and transform the health and care services they provide are what are required to change embedded cultures and climates which may mitigate away from excellent patient care (Robbins 2007). Certainly, the leadership development programme which is the focus of this research was informed and shaped by transformational leadership values, as are many other training programmes in the NHS.

However, this desire to facilitate transformational leadership and the programmes designed to achieve this do not operate in an organisational or political vacuum. 
"This is an accepted manuscript of an article published by Mark Allen Healthcare in British Journal of Healthcare Management, available online at

http://www.magonlinelibrary.com/doi/10.12968/bjhc.2017.23.2.56 it is not the copy of record.

Copyright (C) 2017, Mark Allen Healthcare."

Rather, NHS leadership has to operate within an existing organisational culture and climate much of which is shaped externally via the political needs of government as well as internally shaped by the organisational and clinical needs of good patient care. Key amongst those external factors is achieving externally set targets and a fear of negative publicity surrounding some or all aspects of work (Robertson 2016). Equally, there are internal factors at play including negotiating between clinical and managerial decision making, the role of 'experts' and outside management consultants in shaping policies and practices and the continued presence of a hierarchical structure built around role, types of knowledge and experience (Peate 2016).

As such, according to West et al's (2015) review, there remains a hard core of dominant hierarchical cultures which value rule-setting and targets and see 'work' as a series of tasks to be 'solved' or 'addressed' (Carson et al 2007). Feeding off this culture of target and task-oriented understanding of what constitutes 'good work' is the organisational climate, taken here to mean:

'...a set of attributes which can be perceived about a particular organization and/or its subsystems, and that may be induced from the way that organization and/or its subsystems deal with their members and environment.' (Hellreigell and Slocum 1974).

Thus, both the organisational culture and the organisational climate are central in setting and maintaining successful organisational outcomes. Clearly leadership, as a collective enterprise, will be of paramount importance in shaping organisational change by effecting both culture and climate. However, this supposes that leadership 
"This is an accepted manuscript of an article published by Mark Allen Healthcare in British Journal of Healthcare Management, available online at

http://www.magonlinelibrary.com/doi/10.12968/bjhc.2017.23.2.56 it is not the copy of record.

Copyright (C) 2017, Mark Allen Healthcare."

is immune from the prevailing external and internal influences on health care culture and climate and is able and willing to look beyond the hierarchical and 'expert' leader, task- and target-focussed approach. This is clearly not the case because, as Da Costa (2012: 575) states, in healthcare 'leadership is a social process...' and culture and climate are socially constructed. Whether this is the case and how current leadership groups respond to a challenge which allows them to work outside those twin constraints of culture and climate are at the heart of the research, and it is to this we now turn.

\section{The event}

This event was organised for one the NHS regions and was multi-agency in terms of recruitment of delegates. Health and social care organisations were encouraged to put forward groups of delegates for a two-day residential event. These were existing leadership groups comprised of a representative mix of health and social care professionals ranging from NHS Band 6 up to Chief Executives and clinical consultants. On day one, all groups attended a plenary session where they were introduced to a panel of experts drawn from a range of health and social care organisations including patients' representatives. These experts were all working in health and social care, or were nationally recognised patients' champions, all held senior positions, all had an interest in the field of leadership development and all were advocates of transformational leadership.

Following the plenary, the leadership groups were sent to separate rooms where they were given an imaginary scenario relating to possible future developments in health and social care and asked to address the scenario in whatever way they saw 
"This is an accepted manuscript of an article published by Mark Allen Healthcare in British Journal of Healthcare Management, available online at

http://www.magonlinelibrary.com/doi/10.12968/bjhc.2017.23.2.56 it is not the copy of record.

Copyright (C) 2017, Mark Allen Healthcare."

fit. During the afternoon, the groups were given two interruptions with additional and peripheral scenarios. Groups were provided with the opportunity to call upon members of the expert panel for advice and guidance after the first two hours had elapsed. Day two saw the leadership groups re-convene and prepare a presentation for the panel of experts. Following this, the groups were given a de-briefing session by one of the organising team and by their observer.

It must be noted that the true purpose of the event was to encourage delegates to reflect on their individual and collective leadership styles with the overall aim of helping them become reflexive and flexible leaders who understand and recognise the wide variety of leadership styles needed for the ever-changing health and social care arena. The scenario was simply a vehicle to facilitate that.

This was never articulated to the delegates. They were given no direction as to how to react to the scenario and were left to interpret it in the same manner they would if it were a 'real life' event. So, in effect, the leadership groups were working in their 'normal' way and for research purposes we were able to observe their leadership style in a relatively natural environment.

\section{Methodological approach}

This evaluation employed an on-line questionnaire, delivered a week after the event aimed at gauging the experience of the delegates. This was a 'user friendly' short questionnaire. The questions were a mix of closed questions with the opportunity for respondents to add further qualitative comments if necessary. Data was analysed using a standard software package. 
"This is an accepted manuscript of an article published by Mark Allen Healthcare in British Journal of Healthcare Management, available online at

http://www.magonlinelibrary.com/doi/10.12968/bjhc.2017.23.2.56 it is not the copy of record.

Copyright (C) 2017, Mark Allen Healthcare."

There were 106 delegates and 54 responded to the questionnaire (a response rate of $51 \%)$. In addition, focus group interviews with delegates were held in the month following the event to gain a deeper level insight to how the event was delivered and how lessons learnt may impact on future leadership behaviour. Three focus groups were held $(n=17)$ and three individual interviews with delegates were also undertaken. All interviews and focus group work were recorded and transcribed and analysed against the programmes stated aims.

As part of the overall research project, key providers and leaders from the organising team were also interviewed $(n=4)$. The event itself was observed by a team of nonparticipant independent observers one of which stayed with the panel of experts, one roamed around and across the groups of delegates and each leadership group had their own designated non-participant observer. The observers' task was to be a nonparticipant observer and report back on group dynamics throughout the event. The research was conducted under the ethical protocol of the lead author's institution and following British Sociological Association ethical protocols.

\section{An overview of the findings}

The research generated a wealth of findings. Space precludes a comprehensive review of all the data. What will be presented here is a selection of findings drawn from the focus groups and non-participant observation data which relate to the focus of the paper: the dominance of the 'task-focused, expert-led' approach to leadership.

We first asked the delegates what their initial reaction to the scenario was. Most replied that they had some trepidation about being able to 'deal with' the scenario because they were being asked to address an area of work that they were unfamiliar 
"This is an accepted manuscript of an article published by Mark Allen Healthcare in British Journal of Healthcare Management, available online at

http://www.magonlinelibrary.com/doi/10.12968/bjhc.2017.23.2.56 it is not the copy of record.

Copyright (C) 2017, Mark Allen Healthcare."

with. Observational data shows that all groups immediately problematised the scenario as a task to be 'solved'. Most groups began an internet search to find out more about the area and others began to Google the panel of experts to find out which were more likely to advise them on how to 'solve' it. Equally, all groups fell into a pattern of allowing 'expert' or 'senior' leaders to emerge and dominate despite those individual leaders having no more knowledge or expertise than the other members of the leadership group:

...on reflection, we did exactly what we always do. I was as guilty as everyone else: I simply looked at what we do - who normally does what - and assumed we'd just repeat that pattern for this task...

Once this initial period of uncertainty was over, the leadership groups settled into a task-focused approach to 'solving' the problem. In most instances, this meant that 'senior' leaders delegated tasks, whilst trying to co-ordinate the group and make them focus on a solution. In short, most reverted to a hierarchical approach based on perceived and existing areas of expertise, role and knowledge. Equally, none of the groups considered the possibility of working outside existing organisational frameworks but attempted to 'solve' the problem by recourse to existing formulaic structures. Most sketched out a 'solution' but held-off claiming they had completed the task until the arrival of the independent 'expert' from the panel whose role was seen as being able to verify and confirm their decisions:

We sort of got to a place where we thought we'd answered the questions but, to be honest weren't sure because we didn't feel totally confident in what we'd done. So, we were waiting for the expert to come and reassure us... 
"This is an accepted manuscript of an article published by Mark Allen Healthcare in British Journal of Healthcare Management, available online at

http://www.magonlinelibrary.com/doi/10.12968/bjhc.2017.23.2.56 it is not the copy of record.

Copyright (C) 2017, Mark Allen Healthcare."

There is an irony here. The panel of experts were selected for the event because as individuals they were champions of transformative leadership and avowedly determined to change the prevailing culture and climate of leadership in health and social care. During the event the panel of experts were also given the scenario and asked to address it. What was instructional and illuminating was that when faced with the scenario the experts also problematised the scenario and then adopted the same task-based approach as the groups of delegates, replicating the hierarchical and 'expertise' led approach to 'solving' the problem, even though none of the experts had much knowledge or expertise in the details of the scenario. Like their counterparts in the leadership groups, the health and social care leadership experts resorted to task-focused methods and existing organisational frameworks to construct their solution.

Once a two-hour period had elapsed the groups could call on the experts. These sessions were designed to allow the experts to encourage the groups to reflect on what the leadership process had been and how they had worked as a leadership group, not on how 'successful' they had been on 'solving' the problem. This call for reflection included asking groups to reflect if and how they had facilitated different leadership styles within the group to emerge and flourish, if and how they had approached breaking down existing hierarchies and allowing collective leadership and ownership, and if and how they had explored different ways of group working. It was during this process that most of the delegates found that actually the event was:

\section{Not about skills...but about insight,}


"This is an accepted manuscript of an article published by Mark Allen Healthcare in British Journal of Healthcare Management, available online at

http://www.magonlinelibrary.com/doi/10.12968/bjhc.2017.23.2.56 it is not the copy of record.

Copyright (C) 2017, Mark Allen Healthcare."

Once this became clear, the observational data reports that the leadership groups behaved differently and became more flexible in their approach, recognising that they had reverted to tried and tested methods of working which saw completion of a task as paramount. The focus group interviews reflected this with the phrase 'given permission to do things differently' being used in all three focus group interviews.

Most delegates found this permission powerful and caused them to reflect deeply on how they worked and how their collective leadership impacted on working relationships within and outside their immediate remit:

... it was really powerful to think about how you work. I now know that I'm too passive in meetings and will too readily allow the loudest and most enthusiastic person to lead. I'm not like that: I tend to be slower and perhaps more thoughtful. This has made me realise that my somewhat slower more deliberate style can be an important foil to those who are quicker. I'm going to try to work in tandem with those people who are more spontaneous, rather than allow them to dominate

And;

One thing that was great was it gave us time to re-think our group and who does what and what we might be missing. It will help us recruit in the futurewe now know what type of person we need to balance the group dynamic and help us lead in a different way

However, whilst the event generated enthusiasm for different ways of working and did cause reflection about how leadership is and could be in health and social care, 
"This is an accepted manuscript of an article published by Mark Allen Healthcare in British Journal of Healthcare Management, available online at

http://www.magonlinelibrary.com/doi/10.12968/bjhc.2017.23.2.56 it is not the copy of record.

Copyright (C) 2017, Mark Allen Healthcare."

there was an equal amount of pragmatism (and some pessimism) that maintaining and implementing the leadership lessons learnt from the event would be difficult to sustain in the immediacy of day-to-day working:

I'd like to say it will be all change from this point on. In all honesty, I can't say that. I know that once the pressure is on we'll have to really make an effort not to lapse back...

\section{Discussion}

This paper is not designed to provide definitive answers nor provide the optimal training programme to facilitate transformational leadership. Its purpose is to stimulate thought and discussion around what is seen to be an under-researched area of leadership development in health and social care, based, as it is, on a rigorous academic evaluation. For us, those discussion points need to be around the following research findings:

1. All the leadership groups were working on a hypothetical scenario in a noncompetitive and non-threatening environment. At no time was the scenario presented as a 'problem' and there was no indication that it had to 'solved'. Yet all the leadership groups and the panel of experts problematised the scenario and approached it in a task-focused way.

2. All leadership groups and the panel of experts began their response to the scenario by reverting to, or adopting, a hierarchical leadership framework

where either 'senior' leaders or people with 'expertise' or 'charisma' and 
"This is an accepted manuscript of an article published by Mark Allen Healthcare in British Journal of Healthcare Management, available online at

http://www.magonlinelibrary.com/doi/10.12968/bjhc.2017.23.2.56 it is not the copy of record.

Copyright (C) 2017, Mark Allen Healthcare."

'status' were put at the head of the hierarchy to delegate tasks to others. Within that delegation of tasks individuals adopted their 'normal' work role

3. All leadership groups demonstrated high levels of frustration with the lack of structure and information they had received around the scenario

4. Once the leadership groups had been given 'expert permission' to approach the scenario in a different manner, they adopted a much freer and more group-focused approach to the scenario, abandoning the hierarchical approach.

So, what does this tell us about current leadership and leadership development within health and social care?

It is difficult to make generalisable conclusions from what is essentially a case study but for us it demonstrates the tenacious hold that the current culture and climate which is focused on task-based, problem-solving via an expert-led hierarchical structure has on leadership work. It was clear that even in a situation which was set up for a different way of leading - in essence there was no 'wrong' way to approach the scenario - all participants, even the panel of experts who knew they were there to encourage and facilitate transformational leadership, approached the scenario in a defensive and a task-based manner with 'solutions' being constructed via a hierarchical structure and ultimately dependent upon an expert for validation.

However, once 'permission' to 'do' leadership differently was given by an 'expert' all the groups demonstrated a move to a more collective leadership style, with a mix of leaders and followers emerging. This churn of leaders and followers seemed to stem from a recognition that changes in circumstances often called for a different 
"This is an accepted manuscript of an article published by Mark Allen Healthcare in British Journal of Healthcare Management, available online at

http://www.magonlinelibrary.com/doi/10.12968/bjhc.2017.23.2.56 it is not the copy of record.

Copyright (C) 2017, Mark Allen Healthcare."

leadership style. Thus, most leadership groups adopted a collective, more positive approach to the challenges the scenario presented.

From our findings, it would appear that there is capability and capacity within the current leaders of health and social care to provide leadership which is flexible, innovative and dynamic, devoid of the command and control approach to work. However, the barrier would appear to be a culture and climate-influenced overreliance on the task-based approach and a predilection toward risk and mistake aversion. Once the leadership groups were encouraged to reflect on their own actions, change toward a collective and positive approach happened.

For the future, perhaps a starting point may lie , as Rooke and Tolbert (2005: 161) suggest, at the very top of the NHS and requires a political and corporate approach that trusts leadership and 'helps their executives and leadership teams examine their own action logics...' in order to facilitate wider organisation cultural change.

\section{References}

Carson, J.B., Tesluk, P.E., \& Marrone, J.A. (2007) Shared leadership in teams: an investigation of antecedent conditions and performance, Academy of Management Journal 50, 1217-1234

Da Costa, J. (2012) Leadership models for healthcare improvement, British Journal of Healthcare Management vol 18, no. 11 575-580

Francis, Lord. (2013) Report of the Mid Staffordshire NHS Foundation Trust Public Inquiry The Stationary Office: London 
"This is an accepted manuscript of an article published by Mark Allen Healthcare in British Journal of Healthcare Management, available online at

http://www.magonlinelibrary.com/doi/10.12968/bjhc.2017.23.2.56 it is not the copy of record.

Copyright (C) 2017, Mark Allen Healthcare."

Hellreigell, D., \& Slocum, J. W. (1974) Organisational climate: measures, research and contingencies, Academy of Management Journal 17, 2, 255-280

Kim, Y., \& Newby-Bennett, D (2012) The role of leadership in Learning Culture and Patient Safety, International Journal of Organizational Theory and Behaviour 15, (1) $151-175$

Peate, S. (2016) Leadership needs to be less about hierarchy on line available http://www.leadershipacademy.nhs.uk/blog/leadership-needs-less-hierarchy/ accessed 1.11.2016

Robertson, R. (2016) Six ways which NHS financial pressure can effect patient care The King's Fund: London

Robbins, B. (2007) Transformational leadership in Healthcare Today, Health Care Manager 26, 3, 234-239

Rooke, D, \& Tolbert, W. (2005) Seven transformations of leadership, in On Leadership Harvard Business Review Press: Harvard

West, M., Armit, K., Loewenthal, L, Eckert, R., West, T., \& Lee, A. (2015) Leadership and leadership Development in Health Care. The King's Fund: London 
"This is an accepted manuscript of an article published by Mark Allen Healthcare in British Journal of Healthcare Management, available online at

http://www.magonlinelibrary.com/doi/10.12968/bjhc.2017.23.2.56 it is not the copy of record. Copyright (C) 2017, Mark Allen Healthcare." 